\title{
Knowledge gaps of drug allergy in children: a survey of primary care doctors
}

\author{
Neringa Stirbiene ${ }^{1}$, Odilija Rudzeviciene ${ }^{1}$, Monika Kapitancuke², Neringa Nazarenkaite ${ }^{2}$, Arunas Valiulis ${ }^{1}$
}

${ }^{1}$ Clinic of Children's Diseases, Institute of Clinical Medicine, Faculty of Medicine, Vilnius University, Vilnius, Lithuania ${ }^{2}$ Institute of Clinical Medicine, Faculty of Medicine, Vilnius University, Vilnius, Lithuania

Adv Dermatol Allergol 2021; XXXVIII (1): 63-68

DOI: https://doi.org/10.5114/ada.2021.104280

\begin{abstract}
Introduction: There is still lack of knowledge of drug allergy in children. Proper knowledge and management of drug hypersensitivity reactions is important to physicians.

Aim: To evaluate the approach of primary care doctors regarding drug allergy in children.

Material and methods: A total of 195 primary care doctors were questioned in various parts of Lithuania from 2015 to 2016. An original questionnaire was used. The incidence of a suspected drug allergy, culprit drugs, the clinical pattern and management of the suspected drug hypersensitivity were analysed.

Results: The majority of primary care doctors (74.4\%) reported a suspected drug allergy. The main suspected drugs were antibiotics (95.2\%) and nonsteroidal anti-inflammatory drugs (32.4\%). Skin symptoms (skin rash (100\%) and itching $(82.1 \%)$ ) were the main symptoms of the suspected drug allergy. The vast majority of doctors (93.8\%) withdrew the use of a suspected drug and $68.3 \%$ of respondents prescribed an alternative drug. The fact that skin tests, blood tests and provocation tests could be used in a drug allergy workup were indicated by $43.6 \%$ of doctors. Most doctors (69.2\%) knew about the opportunity to test children for drug allergy in Lithuania and $41.4 \%$ of doctors referred patients for the further drug allergy workup.

Conclusions: The majority of primary care doctors reported a suspected drug allergy in children. The most common suspected drugs were antibiotics and skin symptoms were the main symptoms. Most doctors knew about the possibility to test for the drug allergy but only less than half of them referred patients for the drug allergy workup.

Key words: child, drug hypersensitivity, allergy, primary care, knowledge.
\end{abstract}

\section{Introduction}

Drug allergy is defined as a drug hypersensitivity reaction (DHR) for which a definite immunological mechanism (either drug specific antibodies or T cells) is demonstrated. DHRs are adverse reactions to a drug which clinically resembles drug allergy and DHR is the preferred term when the drug allergy is suspected [1]. There are still no accurate epidemiological data of drug allergy in children. According to a systematic review of published data regarding adverse drug reactions in children, between $0.4 \%$ and $10.3 \%$ of all paediatric hospital admissions can be related with adverse drug reactions and between $0.6 \%$ and $16.8 \%$ of all children exposed to a drug during hospital stay can suffer an adverse drug reaction [2]. Usually parents report a drug allergy of their children and when questioned, approximately $10 \%$ of parents reported their children allergy to drugs [3, 4]. Community-based and self-reporting studies generally tend to overestimate the rates of drug allergy because they evaluate clinical symptoms and history without results of drug allergy workup. After a full allergy workup, only one tenth of these reactions are confirmed as drug allergy on average [3-6]. DHRs hyper diagnostic leads to an increase in morbidity, mortality and treatment cost because an alternative medication is used which can be less effective, more expensive and toxic [7].

Proper knowledge and management of DHRs is important to all physicians. A recent EAACI task force report [8] nicely presented the role of primary care physicians in DHRs diagnostics. Primary care physicians are often

Address for correspondence: Neringa Stirbiene, Clinic of Children's Diseases, Institute of Clinical Medicine, Faculty of Medicine, Vilnius University, Vilnius, Lithuania, e-mail: neringa.stirbiene@santa.It Received: 19.06.2019, accepted: 13.07.2019. 
the first practitioners the patient is consulting when DHR occurs. The primary care physician plays a key role in determining whether to discard the diagnosis of DHR and are responsible for referring to an allergy specialist and for prescribing a safe alternative [8].

Some aspects of DHRs differ between children and adults. Infections, particularly viral infections, are common in children and may act as cofactors, risk factors and are important for differential diagnosis. Suitable paediatric therapeutic alternatives are lacking in many drugs and avoidance is more difficult for children [5]. How physicians interpret DHRs depends on their knowledge of DHRs and affects future patients care.

\section{Aim}

Our intention in this study is to assess the knowledge, attitude and practice of DHRs in children among primary care doctors in Lithuania.

\section{Material and methods}

\section{Study design and study population}

A questionnaire was distributed to primary care doctors who take care of children in their districts in various parts of Lithuania from 2015 to 2016. Doctors practicing exclusively on the adult population were excluded. This study is a part of a study of drug allergy in children in Lithuania approved by the local Ethics Committee.

\section{Questionnaire}

A structured questionnaire in Lithuanian was developed for data collection in electronic and paper form. Apklausa.lt platform was used to electronically develop the questionnaire. The questionnaire contained a total of 10 questions that aimed to collect epidemiological domain (2 questions), practice patterns (6 questions) and general drug allergy knowledge (2 questions) (Table 1).

\section{Data collection}

Data were collected from respondents using a selfadministered questionnaire distributed as paper copies or electronic questionnaires by trained research assistants. The purpose of the study was explained to respondents and consent to the questionnaire was obtained. Respondents filled in a paper copy or electronic questionnaire only. Results of the questionnaire were anonymous and were therefore not stratified by any institution and other parameters. The main information about drug allergy in children, indications for drug allergy workup were provided to physicians after the questionnaires were completed.

\section{Statistical analysis}

The primary objectives were to describe primary care doctors' clinical practice patterns and identify potential knowledge gaps of drug allergy in children. Data were entered into Microsoft Excel 2015, missed or invalid variables were cleaned and imported to SPSS ver. 19.0 (SPSS Inc. Chicago, IL, USA) for analysis. Descriptive statistics were used to describe knowledge and practice exercised by the population of primary care doctors. Means and standard deviations for normally distributed continuous data, frequencies and percentages for categorical data were calculated.

\section{Results}

A total of 195 primary care doctors completed the questionnaire. There are approximately 2000 primary care doctors in Lithuania. Not all of them practice on children in their district. There are no official data on how many doctors take care of children in primary care setting.

Our study population included $488 \pm 337$ (2-1000) children in their districts, 95116 children in total. The most of primary care doctors (145 (74.4\%)) reported a suspected drug allergy in children in their districts and the total number of children with a suspected drug allergy was 1574 (16.6\% of children on average in the respondents' district).

The most common suspected drugs were antibiotics (138 (95.2\%) out of 145 doctors reported), while $\beta$-lactams were reported most frequently, penicillin and amoxicillin were mentioned 91 times. Nonsteroidal anti-inflammatory drugs (NSAIDs) were the second most frequently reported drugs (47 (32.4\%) out of 145 doctors reported) and ibuprofen was reported most frequently from all NSAIDs. Other drugs were reported less frequently (Figure 1). Skin symptoms were the most frequently reported symptoms in the suspected drug allergy: all primary care doctors reported skin rash, 119 (82.1\%) reported itchiness and 66 (45.5\%) reported angioedema. Respiratory and eye symptoms were reported less frequently while cardiovascular and gastrointestinal symptoms were rarely mentioned (Table 2).

We asked our respondents what tactics are used when a drug allergy is suspected to evaluate clinical practice. The majority of primary care doctors (136 (93.8\%) out of 145 ) indicated that they withdrew the use of a suspected drug and 99 (68.3\%) doctors prescribed an alternative medication, whereas 10 (6.9\%) respondents indicated that they continued the treatment with the same medication and added antihistamines and 5 (3.5\%) prescribed other medication from the same drugs class.

Most doctors (69.2\%, 135 out of 195) knew about the opportunity to test children for drug allergy in Lithuania, only 7 (3.6\%) respondents indicated that allergy workup is not performed for drug allergy in children. The fact that skin tests, blood tests and provocation tests could be used in a drug allergy workup were indicated by $43.6 \%$ (85 out of 195) of primary care doctors, some of respon- 
Table 1. Drug allergy questionnaire

\begin{tabular}{|c|c|}
\hline Questions & Possible selections \\
\hline \multicolumn{2}{|l|}{$\begin{array}{l}\text { How many children } \\
\text { are there in your } \\
\text { district? }\end{array}$} \\
\hline \multirow{2}{*}{$\begin{array}{l}\text { Are there any } \\
\text { children with } \\
\text { a suspected drug } \\
\text { allergy in your } \\
\text { district? }\end{array}$} & YES (if YES, how many children?) \\
\hline & NO (if NO, go to question 9) \\
\hline \multirow{8}{*}{$\begin{array}{l}\text { If YES, what drugs } \\
\text { did you suspect? } \\
\text { Check all that apply }\end{array}$} & Antibiotics (state the names) \\
\hline & $\begin{array}{l}\text { Nonsteroidal anti-inflammatory drugs } \\
\text { (NSAIDs) (state the names) }\end{array}$ \\
\hline & Local anaesthetics (state the names) \\
\hline & Anticonvulsants (state the names) \\
\hline & Insulin \\
\hline & lodine (state the names) \\
\hline & Vaccines (state the names) \\
\hline & Other (state the names) \\
\hline \multirow{16}{*}{$\begin{array}{l}\text { What were the } \\
\text { symptoms of your } \\
\text { suspected drug } \\
\text { hypersensitivity } \\
\text { reaction? Check all } \\
\text { that apply }\end{array}$} & Skin rash \\
\hline & Skin itch \\
\hline & Angioedema \\
\hline & Eye redness, itch, watery eyes \\
\hline & Sneezing, rhinorrhoea, nasal obstruction \\
\hline & Dyspnoea \\
\hline & Wheezing \\
\hline & Unconsciousness \\
\hline & Tachycardia \\
\hline & Nausea \\
\hline & Vomiting \\
\hline & Diarrhoea \\
\hline & Hypotension \\
\hline & Headache \\
\hline & Fever \\
\hline & Other (state them) \\
\hline
\end{tabular}

dents indicated one or more of these tests: $38.5 \%$ (75 out of 195) of respondents indicated skin tests, followed by blood tests (21.5\%, 42 out of 195) and provocation tests $(10.3 \%, 20$ out of 195) are used for drug allergy diagnostic. Less than a half of respondents ( $41.4 \%, 60$ out of 145$)$ reported that they referred children with a suspected drug allergy to the allergist and clinical immunologist for further allergy workup.

\section{Discussion}

Primary care doctors do not perform diagnostic tests for drug allergy, but they are responsible for recognizing

\begin{tabular}{|c|c|}
\hline Questions & Possible selections \\
\hline \multirow{3}{*}{$\begin{array}{l}\text { Did the } \\
\text { suspected drug } \\
\text { hypersensitivity } \\
\text { reaction occur in the } \\
\text { hospital? }\end{array}$} & YES \\
\hline & NO \\
\hline & I don’t know \\
\hline \multirow{6}{*}{$\begin{array}{l}\text { What actions were } \\
\text { taken in case of } \\
\text { your suspected drug } \\
\text { hypersensitivity } \\
\text { reaction? Check all } \\
\text { that apply }\end{array}$} & $\begin{array}{l}\text { An alternative medication from the same } \\
\text { drugs class was prescribed }\end{array}$ \\
\hline & $\begin{array}{l}\text { An alternative medication from the } \\
\text { different drugs class was prescribed }\end{array}$ \\
\hline & $\begin{array}{l}\text { Treatment with the same medication } \\
\text { was continued and antihistamines were } \\
\text { added }\end{array}$ \\
\hline & $\begin{array}{l}\text { The use of a suspected drug was } \\
\text { withdrawn }\end{array}$ \\
\hline & No adjustment of the treatment \\
\hline & Other (state them) \\
\hline \multirow{2}{*}{$\begin{array}{l}\text { Have you referred } \\
\text { children with } \\
\text { a suspected drug } \\
\text { hypersensitivity } \\
\text { reaction to an } \\
\text { allergist for the } \\
\text { allergy workup? }\end{array}$} & YES (if YES, go to 8 question) \\
\hline & $\begin{array}{l}\text { NO (if NO, state the reason and go to } \\
\text { question 9) }\end{array}$ \\
\hline \multirow{3}{*}{$\begin{array}{l}\text { Was the } \\
\text { suspected drug } \\
\text { hypersensitivity } \\
\text { reaction confirmed? }\end{array}$} & YES \\
\hline & NO \\
\hline & I don't know \\
\hline \multirow{4}{*}{$\begin{array}{l}\text { What methods are } \\
\text { used in drug allergy } \\
\text { diagnostics? Check } \\
\text { all that apply }\end{array}$} & Skin tests with the suspected drug \\
\hline & $\begin{array}{l}\text { Provocation tests with the suspected } \\
\text { drug }\end{array}$ \\
\hline & Blood tests \\
\hline & All these tests \\
\hline \multirow{3}{*}{$\begin{array}{l}\text { What do you } \\
\text { know about the } \\
\text { opportunity to } \\
\text { test for the drug } \\
\text { allergy in children in } \\
\text { Lithuania? }\end{array}$} & $\begin{array}{l}\text { Children can be tested for the drug } \\
\text { allergy in the tertiary hospital }\end{array}$ \\
\hline & $\begin{array}{l}\text { Testing for the drug allergy is not } \\
\text { performed in children }\end{array}$ \\
\hline & I don't know \\
\hline
\end{tabular}

DHRs and referring the patient to the allergy specialist. In our study, we surveyed current primary care doctors' practice habits on children with a suspected drug allergy and doctors' knowledge of drug allergy. Previous drug allergy studies looked at the prescribing habits and knowledge of doctors in relation to penicillin allergy [9-11] or antibiotics allergy $[12,13]$ or drug allergy $[14,15]$. There is heterogeneity between study [11-15] populations: respondents included doctors, residents, medical students, nurses, and pharmacists. To our knowledge, our study is the first study that looked at knowledge and practice of drug allergy among primary care doctors who take care of children. 


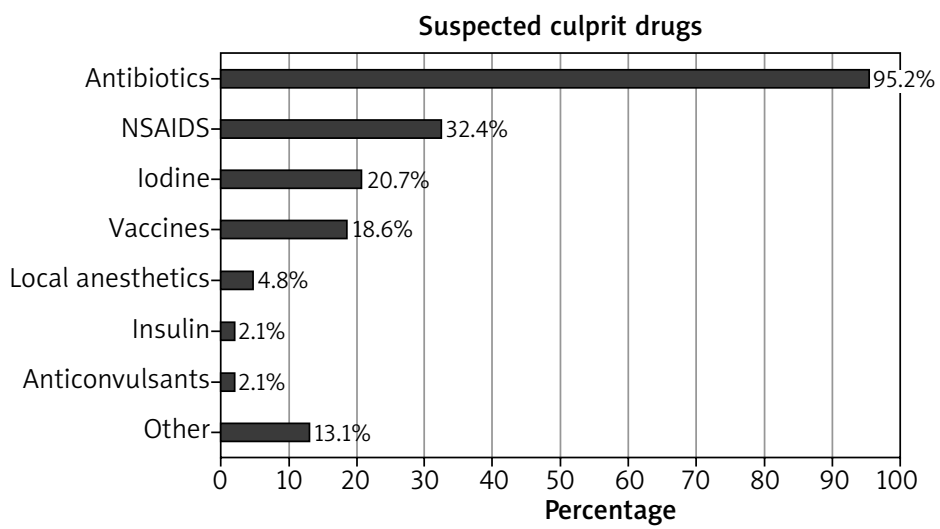

Figure 1. Suspected culprit drugs reported by primary care doctors $(n=145)$

Table 2. Clinical symptoms of drug hypersensitivity reactions reported by primary care doctors

\begin{tabular}{lc}
\hline Symptom & $\begin{array}{c}\text { Frequency of } \\
\text { primary care } \\
\text { doctors reporting } \\
\text { a suspected drug } \\
\text { allergy in their } \\
\text { districts }(n=145)\end{array}$ \\
\hline Skin rash & $100.0 \%$ \\
\hline Skin itch & $82.1 \%$ \\
\hline Angioedema & $45.5 \%$ \\
\hline Eye redness, itch, watery eyes & $22.8 \%$ \\
\hline Sneezing, rhinorrhoea, nasal obstruction & $16.5 \%$ \\
\hline Dyspnoea & $14.5 \%$ \\
\hline Diarrhoea & $11.0 \%$ \\
\hline Nausea & $6.9 \%$ \\
\hline Vomiting & $6.2 \%$ \\
\hline Wheezing & $4.8 \%$ \\
\hline Headache & $3.5 \%$ \\
\hline Tachycardia & $2.8 \%$ \\
\hline Hypotension & $2.1 \%$ \\
\hline Fever & $2.1 \%$ \\
\hline Unconsciousness & $0 \%$ \\
\hline Other & $1.4 \%$ \\
\hline
\end{tabular}

Most respondents reported that there are children with a suspected drug allergy in their districts. The prevalence of drug allergy reported by parents according to studies is approximately less than $10 \%$ of children [3, 4, 16-18]. The reported life-time prevalence of adverse drug reactions in children was $7.5 \%$ [16]. Primary care doctors reported a suspected drug allergy in children in their districts more frequently (16.6\% of children) in our study, we surmise that this finding may be due to doctors noticing symptoms specific to drug allergy more common than parents. In clinical studies where doctors reporting drug allergy were analysed, physicians estimated penicil- lin allergy prevalence to be $5-20 \%$ of their patients [12], $\beta$-lactam antibiotics allergy was $2 \%$ of primary care centre patients [19], any drug allergy was reported to affect $31.8 \%$ of patients [14], the reported incidence of drug allergy at least once a week was for $27 \%$ of general practitioners in Romania and at least once a month was for $30 \%$ of them [20]. When hospital's inpatient electronic medical records were analysed, reports of previous adverse drug reactions were found in $2.6 \%$ of children [21].

The most common reported suspected drugs were $\beta$-lactam antibiotics, followed by NSAIDs. These results are comparable with other studies. Hypersensitivity to this class of drugs is reported by parents and doctors [3, 5], and these drugs were the most common reported culprit drugs in studies carried out in Portugal [4], Germany [16], Turkey [18] and Singapore [21, 22]. $\beta$-Lactam antibiotics most frequently provoke hypersensitivity reactions mediated by the immunologic mechanism. $\beta$-Lactam antibiotics are the first-line treatment for most infections in children, the same applies to NSAIDs (ibuprofen and paracetamol) for fever, pain and inflammation treatment. Other drugs were reported less frequently in our study. Vaccines were mentioned by $18.6 \%$ of primary care doctors in our study. Comparing with parents' questionnairebased survey results, vaccines were responsible for 3.3\% of DHRs [16]. Concerns about any possible allergy to vaccines are frequently raised by parents and healthcare providers and rates of reported vaccine-induced adverse events ranges between 3 and 83 per 100,000 vaccine doses. True hypersensitivity reactions to vaccines are extremely rare, 1-3 per million vaccine doses [23]. One fifth of our respondents mentioned iodine as a suspected medicine in a drug hypersensitivity reaction. The incidence of immediate reactions to intravenous nonionic iodinated radiocontrast media in children is lower than in adults [5]. Local iodine formulations can cause contact dermatitis but are not a risk factor for the development of hypersensitivity to iodinated radiocontrast media [24]. Educational interventions are needed to improve doctors' knowledge and correct misconceptions [25]. 
Skin symptoms caused suspicion of a drug allergy in our respondents. All doctors reported skin rash and majority of them mentioned skin itch. A similar pattern of results was obtained in the study of general practitioners in Romania [20]. Moreover, skin symptoms are the most common reported symptoms in parental reported drug allergy studies $[4,18,22]$. Skin rash caused by infections, particularly viral ones, are common in children and can imitate drug hypersensitivity reactions. Maculopapular exanthema and non-immediate urticarial exanthemas are the most common rashes in suspected DHR in children [5]. Most of skin rashes that occurred during $\beta$-lactam treatment have been suggested due to the infection and drug hypersensitivity has been confirmed in less than $10 \%$ of cases [5]. Urticaria and angioedema were most common manifestations in parents reported NSAID hypersensitivity reactions, but true NSAID hypersensitivity was confirmed in the minority of children [26, 27]. Comorbid conditions such as infections, fever or concomitant use of other drugs may cause skin symptoms in children $[26,27]$. In clinical practice, the majority of children who experienced these symptoms often were labelled as "drug allergic" without any appropriate testing and this diagnosis could persist until adulthood [6].

Respiratory, cardiovascular and gastrointestinal symptoms may be characteristic of drug-induced anaphylaxis, while these symptoms in only one system (e.g. diarrhoea, vomiting, headache) could be a side effect of treatment without any allergic mechanism or were caused by other reasons. Respiratory symptoms were reported less frequently than skin symptoms while cardiovascular and gastrointestinal symptoms were rarely mentioned by primary care doctors in our study. This finding may be a reflection that patients with anaphylaxis are treated in emergency departments and hospitals and usually not in the primary care or primary care doctors recognize these symptoms as side effects.

Drug avoidance is the first step for DHRs management [1]. A study in China demonstrated that $61.8 \%$ of respondents agreed with this statement [15]. In our survey, more than $90 \%$ of respondents withdrew the use of a suspected drug and the majority of doctors prescribed an alternative medication. Most primary care doctors knew about an opportunity to test children for drug allergy in Lithuania and agreed that skin tests, provocation tests and blood tests are used in drug allergy diagnostics. However, some of respondents mentioned one or more but not all of these tests. Skin tests are used for confirming or excluding sensitization but diagnostic values are not fully evaluated for all drugs [1] and it is difficult to assess the value of skin tests in children [5]. The drug provocation test is the gold standard for the identification of the drug inducing the DHR [1]. Trubiano et al. [12] found that $43 \%$ of physicians had skin prick tests or intradermal tests available to them, but only $27 \%$ had combined them with oral provocation tests.
It is particularly remarkable that more than $58 \%$ of primary care doctors in our study indicated that they did not refer children with a suspected drug allergy for further allergist consultation and drug allergy workup. Similar findings have also been reported in a study at two community teaching hospitals, where more than $85 \%$ of respondents indicated that they never or only once per year consult an allergist or immunologist in case of a drug allergy [11], and in a study of general practitioners, in which less than $10 \%$ of patients suspected to have drug allergies received allergist consultation and investigation [20]. Whereas, members of the Emerging Infections Network (EIN) believed that it is worthwhile to refer patients for antibiotic allergy testing to remove the antibiotic allergy label [12]. According parental-reported drug allergy studies, children with a suspected drug allergy were not referred to an allergy specialist [18] or patients were informed about the necessity of further diagnostic procedures but only few children were referred for allergy work-up [16, 22]. When we asked about confirmation of the suspected drug hypersensitivity reaction $45 \%$ of respondents who referred patients for allergy workup stated that the drug allergy was confirmed, but it is difficult to assess how the drug allergy was confirmed.

Our study showed that improvement of primary care doctors' knowledge of drug allergy in children and behaviour that leads to better drug allergy diagnostics is needed. Self-declared gaps in knowledge were expressed for most manifestations of allergy and $61.5 \%$ of primary care doctors reported what type of knowledge of drug reaction/allergy is inadequate [28]. EAACI Task Force report [8] describes the role of the primary care physician in drug allergy diagnostics, indications and contraindications for referring the patient to an allergy specialist and emphasizes a need for education. Recent studies also highlighted a need for further doctors' education in drug allergy [11-15].

The study however does have some limitations. It is possible that the survey may not represent actual practitioners' knowledge, because they may have different interests in drug allergy and those who are more concerned tend to respond to the questionnaire. In addition to this, respondents have different children populations in their districts. Also, questions in the questionnaire may have limitations because they are more general and cannot evaluate all aspects in different clinical cases. Future studies involving large sample size and intervention studies to attempt to improve doctors' knowledge of drug allergy in children would be useful.

\section{Conclusions}

These study findings demonstrate educational gaps in knowledge and practice concerning drug allergy in children in the primary care setting. The majority of primary care doctors reported a suspected drug allergy in 
children and the most common suspected drugs were antibiotics and NSAIDs. Skin symptoms were the main symptoms of the suspected drug allergy. The majority of primary care doctors knew about the possibility to test for the drug allergy but only less than half of them referred patients for the allergy workup. Incorporation of allergy teaching into primary care physicians' training programs and undergraduate medical teaching are likely to have a significant impact on better drug allergy diagnostics.

\section{Conflict of interest}

The authors declare no conflict of interest.

\section{References}

1. Demoly P, Adkinson NF, Brockow K, et al. International Consensus on drug allergy. Allergy Eur J Allergy Clin Immunol 2014; 69: 420-37.

2. Smyth RMD, Gargon E, Kirkham J, et al. Adverse drug reactions in children - a systematic review. PLoS One 2012; 7 : e24061.

3. Erkocoglu M, Kaya A, Civelek E, et al. Prevalence of confirmed immediate type drug hypersensitivity reactions among school children. Pediatr Allergy Immunol 2013; 24: 160-7.

4. Rebelo Gomes E, Fonseca J, Araujo L, et al. Drug allergy claims in children: from self-reporting to confirmed diagnosis. Clin Exp Allergy 2008; 38: 191-8.

5. Gomes ER, Brockow K, Kuyucu S, et al. Drug hypersensitivity in children: report from the pediatric task force of the EAACl Drug Allergy Interest Group. Allergy 2016; 71: 149-61.

6. Caubet JC, Kaiser L, Lemaître B, et al. The role of penicillin in benign skin rashes in childhood: a prospective study based on drug rechallenge. J Allergy Clin Immunol 2011; 127: 218-22.

7. Satta G, Hill V, Lanzman M, et al. $\beta$-lactam allergy: clinical implications and costs. Clin Mol Allergy 2013; 11: 2.

8. Dońa I, Caubet JC, Brockow K, et al. An EAACI task force report: recognising the potential of the primary care physician in the diagnosis and management of drug hypersensitivity. Clin Transl Allergy 2018; 8: 16.

9. Puchner TC, Zacharisen MC. A survey of antibiotic prescribing and knowledge of penicillin allergy. Ann Allergy Asthma Immunol 2002; 88: 24-9.

10. Solensky R, Earl HS, Gruchalla RS. Clinical approach to penicillin-allergic patients: a survey. Ann Allergy Asthma Immunol 2000; 84: 329-33.

11. Staicu ML, Soni D, Conn KM, et al. A survey of inpatient practitioner knowledge of penicillin allergy at 2 community teaching hospitals. Ann Allergy Asthma Immunol 2017; 119: 42-7.

12. Trubiano JA, Beekmann SE, Worth LJ, et al. Improving antimicrobial stewardship by antibiotic allergy delabeling: evaluation of knowledge, attitude, and practices throughout the emerging infections network. Open Forum Infect Dis 2016; 3: ofw153.

13. Trubiano JA, Worth LJ, Urbancic K, et al. Return to sender: the need to re-address patient antibiotic allergy labels in Australia and New Zealand. Intern Med J 2016; 46: 1311-7.
14. Sturm JM, Temprano J. A survey of physician practice and knowledge of drug allergy at a university medical center. J Allergy Clin Immunol Pract 2014; 2: 461-4.

15. Wang Y, Zhu R, Huang N, et al. Knowledge, attitudes, and practices survey of drug allergy among healthcare practitioners in central China: a multicenter study. Asia Pac Allergy 2016; 6: 105-11.

16. Lange L, Koningsbruggen SV, Rietschel E. Questionnairebased survey of lifetime-prevalence and character of allergic drug reactions in German children. Pediatr Allergy Immunol 2008; 19: 634-8.

17. Martins P, Belo J, Marques J, et al. Reported drug allergy among children attending day care centers. Acta Med Port 2014; 27: 444-9.

18. Orhan F, Karakas T, Cakir M, et al. Parental-reported drug allergy in 6- to 9-yr-old urban schoolchildren. Pediatr Allergy Immunol 2008; 19: 82-5.

19. Salden OAE, Rockmann H, Verheij TJM, et al. Diagnosis of allergy against beta-lactams in primary care: prevalence and diagnostic criteria. Fam Pract 2015; 32: 257-62.

20. Leru PM. Drug allergies in primary care practice in Romania: a questionnaire-based survey. Allergy Asthma Clin Immunol 2014; 10: 2-4.

21. Kidon MI, See Y. Adverse drug reactions in Singaporean children. Singapore Med J 2004; 45: 574-7.

22. Tan VAK, Gerez IFA, Van Bever HP. Prevalence of drug allergy in Singaporean children. Singapore Med J 2009; 50: 1158-61.

23. Caubet JC, Rudzeviciene O, Gomes E, et al. Managing a child with possible allergy to vaccine. Pediatr Allergy Immunol 2014; 25: 394-403.

24. Rosado Ingelmo A, Dońa Diaz I, Cabańas Moreno R, et al. Clinical practice guidelines for diagnosis and management of hypersensitivity reactions to contrast media. J Investig Allergol Clin Immunol 2016; 26: 144-55.

25. Westermann-Clark E, Pepper AN, Talreja N, et al. Debunking myths about "allergy" to radiocontrast media in an academic institution. Postgrad Med 2015; 127: 295-300.

26. Alves C, Romeira AM, Abreu C, et al. Non-steroidal antiinflammatory drug hypersensitivity in children. Allergol Immunopathol 2017; 45: 40-7.

27. Yilmaz O, Ertoy Karagol IH, Bakirtas A, et al. Challenge-proven nonsteroidal anti-inflammatory drug hypersensitivity in children. Allergy 2013; 68: 1555-61.

28. Ryan D, Angier E, Gomez M, et al. Results of an allergy educational needs questionnaire for primary care. Allergy Eur J Allergy Clin Immunol 2017; 72: 1123-8. 